\title{
Amélie Calderone, Le Proverbe dramatique de Théodore Leclercq: modèle comique pour dramaturges romantiques
}

\section{Valentina Ponzetto}

\section{(2) OpenEdition \\ Journals}

Édition électronique

URL : http://journals.openedition.org/studifrancesi/1529

DOI : 10.4000/studifrancesi. 1529

ISSN : 2421-5856

Éditeur

Rosenberg \& Sellier

Édition imprimée

Date de publication : 1 novembre 2014

Pagination : 608

ISSN : 0039-2944

\section{Référence électronique}

Valentina Ponzetto, "Amélie Calderone, Le Proverbe dramatique de Théodore Leclercq: modèle comique pour dramaturges romantiques », Studi Francesi [En ligne], 174 (LVIII | III) | 2014, mis en ligne le 01 novembre 2014, consulté le 18 septembre 2020. URL : http://journals.openedition.org/studifrancesi/ 1529 ; DOI : https://doi.org/10.4000/studifrancesi.1529

Ce document a été généré automatiquement le 18 septembre 2020.

\section{cc) $(9)$}

Studi Francesi è distribuita con Licenza Creative Commons Attribuzione - Non commerciale - Non opere derivate 4.0 Internazionale. 


\title{
Amélie Calderone, Le Proverbe dramatique de Théodore Leclercq: modèle comique pour dramaturges romantiques
}

\author{
Valentina Ponzetto
}

\section{RÉFÉRENCE}

AMÉLIE CALDERONE, Le Proverbe dramatique de Théodore Leclercq: modèle comique pour dramaturges romantiques, «Orages», n. 13, mars 2014, pp. 241-256.

1 Cet article a essentiellement le mérite d'étudier la dramaturgie de Théodore Leclercq, auteur d'une importante collection de proverbes dramatiques fort lue et très appréciée sous la Restauration et la Monarchie de Juillet, mais presque oubliée aujourd'hui. Il éclaire d'abord le trait distinctif de l'écriture dramatique de Leclercq, c'est-à-dire la prédominance du discours, voire de la conversation, sur l'action, ensuite le rapport des proverbes de Leclercq avec la presse périodique où ils ont souvent vu le jour, et enfin leur postérité, notamment auprès de dramaturges romantiques.

2 Pour étayer sa démonstration, Amélie Calderone choisit de comparer systématiquement Leclercq avec Scribe, et plus spécifiquement deux cas où le même sujet a été traité par les deux écrivains: Les Adieux du comptoir (1824) de Scribe et La Bonne Maman (1832) de Leclercq, déclinaisons du thème de la jeune fille à marier qui doit choisir entre un riche commerçant et un noble, et Le Plus Beau Jour de la vie, proverbe de Leclercq sur les désillusions du marriage, publié en 1824 et adapté l'année suivante par Scribe sous forme de vaudeville pour le Gymnase. L'analyse démontre de manière évidente que, là où Scribe privilégie le comique de situation, les stratagèmes et les rebondissements de l'intrigue, si petits et quotidiens soient-ils, Leclercq mise plutôt sur la réflexion, le dialogue et les sentiments des personnages. On pourra cependant 
objecter que ces choix dépendent sans doute plus que l'auteur ne veut l'admettre d'un choix générique préalable (proverbe pour la lecture ou la mise en scène sur un théâtre de société versus vaudeville pour le Gymnase), et surtout qu'ils n'impliquent pas forcément une supériorité de Leclercq sur Scribe, comme elle semble le suggérer par inclination personnelle ou par provocation argumentative.

3 De même, affirmer l'interdépendance du proverbe et de la diffusion dans la presse périodique de l'étude de mœurs et de la forme dialogique équivaut sans doute à forcer un peu la réalité pour soutenir une thèse certes intéressante. Il reste, comme le rappelle justement Amélie Calderone, l'indéniable valeur des proverbes en revue de Leclercq en tant que promoteurs de la «démocratisation d'un modèle élitaire de comédie» (p. 250) et précurseurs des plus hautes réalisations de Musset, Sand, Vigny ou Gautier dans le domaine de la comédie moderne et littéraire, opposée au comique facile du vaudeville. 